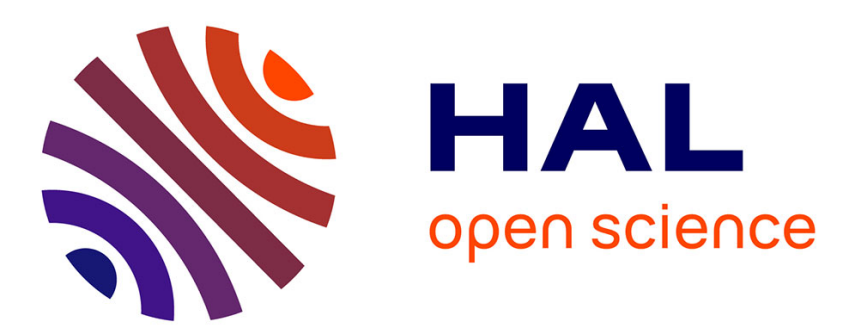

\title{
Xenopus Rbm9 is a novel interactor of XGld2 in the cytoplasmic polyadenylation complex.
}

Catherine Papin, Christel Rouget, Elisabeth Mandart

\section{To cite this version:}

Catherine Papin, Christel Rouget, Elisabeth Mandart. Xenopus Rbm9 is a novel interactor of XGld2 in the cytoplasmic polyadenylation complex.. FEBS Journal, 2008, 275 (3), pp.490-503. 10.1111/j.17424658.2007.06216.x . hal-00246533

\section{HAL Id: hal-00246533 \\ https://hal.science/hal-00246533}

Submitted on 3 Mar 2008

HAL is a multi-disciplinary open access archive for the deposit and dissemination of scientific research documents, whether they are published or not. The documents may come from teaching and research institutions in France or abroad, or from public or private research centers.
L'archive ouverte pluridisciplinaire HAL, est destinée au dépôt et à la diffusion de documents scientifiques de niveau recherche, publiés ou non, émanant des établissements d'enseignement et de recherche français ou étrangers, des laboratoires publics ou privés. 


\section{Xenopus Rbm9 is a novel interactor of XGId2 in the cytoplasmic polyadenylation complex.}

Catherine Papin ${ }^{\S}$, Christel Rouget ${ }^{\S}$ and Elisabeth Mandart

Centre de Recherche en Biochimie Macromoléculaire,

UMR 5237 Université Montpellier II- CNRS,

1919, route de Mende, 34293 Montpellier cedex 5, France.

http://www.crbm.cnrs.fr/

Running title: XRbm9, a novel XGld2 interactor.

Subdivision: Developmental biology

Corresponding author:

Catherine Papin,

e-mail: catherine.papin@igh.cnrs.fr, Tel (33) 49961 99 59, Fax (33) 499619901

Elisabeth Mandart,

e-mail: elisabeth.mandart@crbm.cnrs.fr

$\S_{\text {Present address: }}$

Régulation des ARNm et Développement, Institut de Génétique Humaine

141, rue de la Cardonille, 34396 Montpellier cedex 5, France.

Abbreviations: PAP, poly(A) polymerase; CPEB, cytoplasmic polyadenylation elementbinding protein; Gal4BD, Gal4 DNA binding domain

Keywords: Gld2, cytoplasmic polyadenylation, Xenopus oocyte, Rbm9, poly(A)polymerase.

Data deposition: AM419007, AM419008, AM419009, AM419010 


\begin{abstract}
During early development, control of the poly(A) tail length by cytoplasmic polyadenylation is critical for regulating specific mRNA expression. Gld2, an atypical poly(A) polymerase, has been involved in cytoplasmic polyadenylation in Xenopus oocytes. In this study, we identify a new XGld2-interacting protein: XRbm9. This RNA-binding protein is exclusively expressed in the cytoplasm of Xenopus oocytes and interacts directly with XGld2. We show that XRbm9 belongs to the cytoplasmic polyadenylation complex along with CPEB, CPSF and XGld2. In addition, tethered XRbm9 stimulated translation of a reporter mRNA. We also analyzed XGld2 function in stage VI oocytes. The injection of XGld2 antibody into oocytes inhibited polyadenylation showing that endogenous XGld2 is required for cytoplasmic polyadenylation. Unexpectedly, XGld2 as well as CPEB antibody injections also led to an acceleration of meiotic maturation suggesting that XGld2 is part of a masking complex with CPEB and is associated with repressed mRNAs in oocytes.
\end{abstract}




\section{Introduction}

Translational regulation of mRNA is often linked to the control of the poly(A) tail length since its cytoplasmic lengthening can stabilize mRNA and activate translation. During early development, control of the poly(A) tail length by cytoplasmic polyadenylation is critical for regulating specific mRNA expression [1].

The molecular mechanisms that underlie the regulation of polyadenylation-dependent translation are well documented especially in Xenopus oocytes. Elements located in the 3'untranslated region (3'UTR) have been implicated in the regulation of cytoplasmic polyadenylation of maternal mRNAs. Amongst them, the cytoplasmic polyadenylation element (CPE) is bound by CPEB (CPE binding protein) [2], a critical regulator of cytoplasmic polyadenylation that can display opposite roles in the regulation of translation. On one hand, CPEB represses translation of CPE-containing mRNAs via its interaction with other partners, including Maskin, the RNA helicase Xp54 and Pumilio [3-5]. Maskin interacts simultaneously with both CPEB and the eukaryotic initiation factor eIF4E. This interaction interferes with the formation of eIF4F, a complex required for translational initiation, and therefore represses translation. On the other hand, CPEB has a positive role in promoting translational activation of target RNAs by cytoplasmic polyadenylation. CPEB belongs to a complex with the Cleavage and Polyadenylation Specificity Factor (CPSF), that binds to another essential cis element, the hexanucleotide AAUAAA, with the scaffold protein Symplekin, the poly(A) polymerase (PAP) and the PARN deadenylase [6.7]. Meiotic reactivation by progesterone addition leads to CPEB phosphorylation and activation of the complex which allow the PAP to elongate the poly(A) tail [6.7]. Then, the poly(A) tail binds to the poly(A)-binding protein (PABP), which brings in eIF4G, thus allowing the positioning of the 40s ribosomal subunit on the 5'end of the mRNA and the translation of specific mRNAs [8]. Additional proteins binding to other specific sequences at the 3'UTR of mRNAs have also been characterized [5.9] suggesting that other transcript-specific complexes are present at the 3'UTR of regulated mRNAs.

Although cytoplasmic polyadenylation is regulated by a protein complex at the mRNA 3'end, PAP is the only known enzyme capable of elongating the poly(A) tail. This activity was thought to be performed only by the canonical PAPs which are present in Xenopus oocytes [10.11]. Yet, PAPs from another family, called Gld2, and distinct from canonical PAPs have been characterized in yeast, C. elegans, Xenopus and mammals [12-14]. CeGLD-2 is required for progression through meiotic prophase and promotes entry into meiosis from the mitotic 
cell cycle [15]. Its polymerase activity is stimulated by interaction with an RNA binding protein, GLD-3, forming a heterodimeric PAP with GLD-2 as the catalytic subunit [16]. GLD-2 homologs displaying polyadenylation activity were also identified in mice and human [17-19]. In Xenopus, XGld2 has been identified as a component of the cytoplasmic polyadenylation complex along with CPEB, CPSF, Symplekin and CstF-77 [6.19.20]. Interestingly, XGld2 does not interact with the repressor factors Maskin and Pumilio, implying that the PAP is not associated with this repressive complex [19]. Therefore, CPEB and CPSF appear to be factors that are important in recruiting XGld2 to CPE-containing mRNA although other RNA binding proteins might as well be involved. In vitro studies have shown that XGld2 is involved in cytoplasmic polyadenylation [6] but its role in stage VI oocytes and during oocyte meiotic maturation has not been addressed.

The RNA-binding protein Rbm9 (also known as Fox2, fxh and RTA) is part of a family of proteins that includes A2BP1 (also called Fox1) and HRNbp3. Several of these homologs have been identified in mammals, zebrafish, Drosophila and worm [21.22]. A2BP1 and Rbm9 are involved in the regulation of alternative splicing in muscle and the nervous system and they operate through their binding to an intronic splicing enhancer in mammals [22-25]. RTA was shown to act as a negative regulator of the human estrogens receptor transcriptional activity [26].

In this study, we identify XRbm9 as a new XGld2-interacting protein. This RNA-binding protein is only detected in the cytoplasm of Xenopus oocytes and it belongs to the cytoplasmic polyadenylation complex with CPEB, CPSF and XGld2. In addition, tethered XRbm9 stimulates translation of a reporter mRNA. We also analyze XGld2 function in stage VI oocyte. Using specific antibody, we show that endogenous XGld2 is required for cytoplasmic polyadenylation and that XGld2 is probably part of a masking complex with CPEB in oocytes.

\section{Results}

\section{Identification of Rbm9 as a Gld2 interacting protein}

Like other members of the Gld2 family, XGld2 lacks any recognizable RNA binding domain suggesting that other factors should associate with the polymerase to determine which RNAs will undergo polyadenylation. To identify XGld2 associated-proteins, we performed a yeast two-hybrid screen. Because of the lack of a good quality Xenopus cDNA library, a human embryonic cDNA library was used as prey. Both the N-terminal (hGld2N) and the C-terminal 
(hGld2C) parts of hGld2 (Fig.1A) were fused to the Gal4 DNA binding domain (Gal4 BD) and used as baits. After sequencing the putative Gld2-interacting candidates, three independent cDNA clones were shown to correspond to a putative RNA binding protein encoded by Rbm9 (RNA binding motif protein 9). Therefore, we designated our isolated cDNA as hRbm9. The mammalian Rbm9 gene has multiple promoters and numerous alternative splicing events that give rise to a large family of proteins with variable $\mathrm{N}$ and $\mathrm{C}$ termini and internal deletions. Information relevant to its sequence is presented as supplementary data (Fig.S1). Only those yeast strains coexpressing hGld2 or hGld2N and hRbm9 were able to grow in medium lacking histidine, whereas hGld2C/hRbm9 cotransformants did not elicit any growth (Fig.1B). These results indicate that the N-terminal part of hGld2 (amino acids 1-185) interacts directly with hRbm9 in a yeast two-hybrid assay. Coimmunoprecipitation experiments in rabbit reticulocyte lysate (RRL) and Xenopus oocytes using HA-tagged hRbm9 showed that hRbm9 associates with XGld2 and CPEB in RRL and in ovo (data not shown).

Based on these results, we surmised that Rbm9 protein might be present in Xenopus oocytes. Using the hRbm9 sequence in a BLAST search, we identified Xenopus leavis ESTs (expressed sequence tag) that yielded a complete open reading frame (ORF). A cDNA sequence containing the full length ORF was isolated by RT-PCR from oocyte total RNA. The 411 amino acid ORF contains a single central RNA recognition motif (RRM)-type RNA binding domain with two RNP domains (Fig.1C and S1). In addition, the ORF contains two arginine/glycine-rich (RGG) motifs that are characteristic of RNA binding proteins and an alanine-rich carboxy-terminal sequence that could be involved in protein-protein interactions. Interestingly, this alanine-rich sequence, generated by alternative splicing, is not present in the hRbm9 isolated in the screen (Fig.S1). Sequence comparison with hRbm9 shows an overall 59\% similarity, which rises to $98 \%$ for the RNA binding domain (Fig.1C). Therefore, we now refer to this cDNA as XRbm9.

To study the biological role of XRbm9 in Xenopus oocytes, an XRbm9 antibody was raised (Fig.S2) and used to examine the abundance and localization of endogenous XRbm9 in oocytes (Fig.1D). A single endogenous protein of about $55 \mathrm{kDa}$, comigrating with the in vitro translated XRbm9 protein (lane 1), was present in stage VI and mature oocytes (lanes 2,3). Interestingly, XRbm9 was exclusively detected in the oocyte cytoplasm (lane 4). Western blot analysis showed that XRbm9 is expressed throughout oogenesis, oocyte maturation and during embryogenesis up to stage 33 (Fig.1E). These data identify a novel Gld2-interacting protein, XRbm9 which is expressed in the oocyte cytoplasm. 


\section{XRbm9 is a component of the cytoplasmic polyadenylation complex}

We next investigated the interactions between the XGld2 and XRbm9 by yeast two-hybrid analyses. Human and Xenopus Rbm9 and Gld2 can interact with each other reciprocally (Fig.2A). Deletion constructs showed that the Gld2-Rbm9 interaction is mediated by the Gld2 $\mathrm{N}$-terminal domain. Interestingly, the N-terminal parts of Xenopus and human Gld2 only share 36\% similarity. Moreover, XGld2D4, a splice variant (shown in Fig.S4) interacts with Rbm9, but the N-terminal part of this variant (XGld2D4N) does not. These data suggest that the interacting domain in the $\mathrm{N}$-terminal region of Gld2 is more likely to be conformational than a definite sequence. Conversely, Rbm9 N-terminal most residues are not required for the Gld2-Rbm9 interaction (Fig.2B). However, the RRM-containing central domain of hRBm9 (amino acid 48 to 269) or the hRbm9 269-350 are not ABLE to mediate the binding. These data suggest that A DOMAIN SURROUNDING THE AMINO ACID 269 IS IMPORTANT FOR THE INTERACTION or that most of the Rbm9 sequence is required for the interaction. HOWEVER, WE CANNOT RULE OUT THAT THE SMALLER REGIONS OF HRBM9 (HRBM9 48-269 OR HRBM9 269-350) ARE NOT SUFFICIENTLY EXPRESSED IN YEAST TO DETECT AN INTERACTION.

To test whether XRbm9 interacts with polyadenylation factors in ovo, we performed coimmunoprecipitation experiments under various conditions using our specific XRbm9 antibody. The injection of HA-tagged XRbm9 $\Delta \mathrm{N}(55-411)$ into oocytes and precipitation with HA antibody in the presence of RNaseA show that endogenous XGld2 and CPEB are specifically immunoprecipitated with overexpressed XRbm9 (Fig.2C, top panel). Overexpressed HA-XRbm9 is also detected in XGld2 and CPEB immunoprecipitates (Fig.2C, bottom panel). Alternatively, HA-tagged XGld2 was overexpressed in oocytes and the lysates were immunoprecipitated with XRbm9, XGld2, CPEB antibodies or a control IgG in the presence of RNaseA (Fig.2D). This condition allows us to coprecipitate endogenous XRbm9 with XGld2 and CPEB. Reciprocally, overexpressed XGld2 and endogenous CPSF100 and CPEB were coprecipitated with the XRbm9, CPEB and XGld2 antibodies. Finally, in oocytes that do not overexpress exogenous proteins, endogenous XRbm9 was coimmunoprecipitated with the XGld2 and CPEB antibodies (Fig.2E). Reciprocally, CPEB was present in the $\mathrm{XRbm} 9$ and XGld2 precipitates. 
Together, these results show that endogenous XRbm9 belongs to a complex with XGld2, CPEB and CPSF independently of an RNA intermediate and possibly through its direct interaction with XGld2.

\section{XRbm9 stimulates translation in Xenopus oocytes}

Since XRbm9 is associated with the polyadenylation complex, we investigated whether XRbm9 was required for cytoplasmic polyadenylation in oocytes. XRbm9 antibody was injected into oocytes in order to interfere with the endogenous protein and mos mRNA polyadenylation was scored using a polyadenylation test (PAT assay). XRbm9 antibody injection did not affect the progesterone-induced polyadenylation extent of the reporter RNA (Fig.S3) and had no effect on meiotic maturation (data not shown). These data indicate that either XRbm9 is not required for cytoplasmic polyadenylation in oocytes or that the XRbm9 antibody was not able to prevent XRbm9 function.

We hence investigated the role of XRbm9 with the tethered approach that has been used to study the function of proteins involved in mRNA stability or translation [27-29]. XRbm9 protein was fused to the MS2 coat protein that allowed tethering XRbm9 to a reporter mRNA bearing a tandem pair of MS2-binding sites. Oocytes were first injected with the MS2XRbm9-encoding mRNA or MS2 alone and MS2-U1A as negative controls. As positive control, MS2-PABP, known to stimulate translation in oocytes, was also injected [28]. After 6 hours incubation to allow protein synthesis, two reporter mRNAs were coinjected: a firefly luciferase mRNA bearing MS2 binding sites in its 3'UTR and an internal control mRNA encoding the Renilla luciferase. After another $16 \mathrm{~h}$ incubation, both luciferase activities were determined. MS2-XRbm9 expression stimulated the luciferase activity of about six fold compared to the MS2 protein alone (Fig.3A). This activation was comparable to that obtained with MS2-PABP. This activation was cis-dependent since MS2-XRbm9 or MS2-PABP fusion proteins did not affect the expression of firefly luciferase reporter mRNA lacking the MS2 binding sites (Luc $\Delta \mathrm{MS} 2$ ). As expected, the control MS2-U1A did not stimulate translation regardless of whether MS2 binding sites were or not present. Moreover, similar levels of all MS2 fusion proteins were expressed in the oocytes (Fig.3B). These experiments show that tethered XRbm9 is able to activate the translation of reporter mRNA in oocytes.

We then investigated how tethering XRbm9 protein to an mRNA could stimulate translation. As a XGld2-interacting protein, XRbm9 could enhance translation by targeting XGld2 to the mRNA and allowing its polyadenylation which would enhance its translation. TO ASSESS 
THIS ISSUE DIRECTLY, A TETHERED ASSAY WAS PERFORMED WHERE MS2XRBM9 WAS CO-INJECTED WITH THE HA-TAGGED CATALYTICALLY INACTIVE FORM OF XGLD2 (XGLD2 D242A). AS SHOWN IN FIGURE 3C, OVEREXPRESSION OF XGLD2 D242A (FIGURE 3D) DOES NOT AFFECT THE TRANSLATIONAL ACTIVATION BY MS2-XRBM9. MOREOVER, THE OVEREXPRESSION OF THE WILD-TYPE FORM OF XGLD2 DOES NOT POTENTIATE THE STIMULATION OF THE LUCIFERASE ACTIVITY BY MS2-XRBM9. THESE DATA SUGGEST THAT THE TRANSLATIONAL ACTIVATION BY THE TETHERED XRBM9 IS NOT DEPENDENT ON XGLD2. THIS EXPERIMENT ALSO SHOW THAT THE TRANSLATIONAL ACTIVATION BY MS2-XRBM9 IS COMPARABLE TO THE ONE OBTAINED WITH MS2-XGLD2.

\section{XGId2 antibody injection accelerates the G2/M transition in Xenopus oocytes}

During the course of our experiments, we noticed that the XGld2 antibody was able to affect the endogenous XGld2 function (Fig.S3). XGld2 interacts with the polyadenylation factors CPEB and CPSF in oocytes [6.19]. However, up to now, AN antibody directed against XGld2 has not been used to study Gld2 function in oocyte. The difficulty in visualizing endogenous XGld2 with a specific antibody might be due its low amounts in frog eggs. Using our specific XGld2 antibody (Fig.S4A-C), we were able to detect both the endogenous (Fig.4A, lanes 2,3), the overexpressed (lane 4) and HA-tagged (lane 1) XGld2 proteins by Western blotting. The antibody can also specifically immunoprecipitate endogenous XGld2 protein (Fig.4A, lane 7). In addition, we were able to detect CPEB and CPSF160 in the XGld2 immunoprecipitates showing that, consistent with the overexpression studies, immunoprecipitated endogenous XGld2 is associated with CPEB and CPSF (Fig.4A, lanes 11-13).

We, therefore, took advantage of this specific XGld2 antibody to address XGld2 function in meiotic maturation. The antibody was injected into oocytes induced to maturate with progesterone. Unexpectedly, XGld2 antibody injection accelerated the G2/M transition as compared to control (i.e., IgG-injected or uninjected) oocytes (Fig.4B). XGld2 antibodyinjected oocytes underwent 50\%GVBD 2 hours before control oocytes suggesting an acceleration of the $\mathrm{G} 2 / \mathrm{M}$ transition in meiosis I. This hastening of maturation was correlated with a precocious synthesis of Mos and AuroraA proteins and with the activation of the MAPK (Fig.4C). To confirm these findings, we interfered with the function of CPEB, another protein involved in mRNA masking. Injection of CPEB antibody led to similar results on progesterone-induced oocyte maturation and on the molecular markers (Fig.4D and E). 
Moreover, CPEB antibody injection in oocytes without progesterone treatment led to a mild but reproducible activation of ERK (Fig.4F, see discussion).

Thus, affected XGld2 or CPEB functions lead to accelerated progesterone-induced oocyte maturation suggesting that XGld2, as CPEB and, as we previously showed, CstF-77 [20], belongs to a masking complex in oocytes.

\section{XGId2 antibody inhibits cytoplasmic polyadenylation in Xenopus oocytes}

We tested whether the activity of endogenous XGld2 polymerase was required for cytoplasmic polyadenylation in Xenopus oocytes using XGld2 antibody. In vitro polyadenylation test in egg extracts was not possible as XGld2 antibody was not able to deplete the polymerase from the extracts. Therefore, XGld2 or CPEB antibodies were injected into oocytes and exogenous mos mRNA polyadenylation was scored using the PAT assay. While progesterone induced robust polyadenylation of the reporter RNA (Fig.5A, lanes 2 and 3 and Fig.S3), a decrease in both the length of the poly(A) tail and the overall extent of polyadenylation was observed when XGld2 antibody was injected (lane 5). Injection of CPEB antibody also prevented poly(A) tail elongation (lane 4). Inhibition of polyadenylation by XGld2 antibody was also detected during a kinetic of maturation (Fig.5B) were the reduction in the poly(A) tail length was observed as soon as $1 \mathrm{~h}$ after progesterone addition (compare lane 3 with lane 8). These data represent a direct evidence that endogenous XGld2 is required for cytoplasmic polyadenylation in maturing oocytes.

Taken together, these results demonstrate that endogenous XGld2 is a component of the cytoplasmic polyadenylation machinery and is required for this regulatory event.

\section{Discussion}

In this paper, we identify a new XGld2-interactor, the RNA binding protein XRbm9 and demonstrate that it is part of a complex with Gld2, CPEB and CPSF and that tethered XRbm9 via the MS2 protein stimulates translation. We also show that endogenous XGld2 is required for cytoplasmic polyadenylation and is PROBABLY part of a masking complex with CPEB in stage VI oocyte.

Using a specific antibody, we interfered with endogenous XGld2 and assessed, for the first time, its function in vivo. We find that XGld2 antibody injection leads to an inhibition of mos mRNA cytoplasmic polyadenylation corroborating the significant role of XGld2 in cytoplasmic polyadenylation during meiotic maturation. Intriguingly, XGld2 as well as CPEB 
antibody injection also lead to an acceleration of progesterone-induced oocyte maturation. This dual effect of an antibody was already reported during the study of p82, the clam CPEB homolog [30] where the authors propose that p82 has two functions, one in masking in immature oocytes and subsequently, in the activation of translation by cytoplasmic polyadenylation. It was previously reported that CPEB antibody injection led to an inhibition of meiotic maturation [31]. However, later studies implicated CPEB in mRNA masking in oocyte [3.30.32.33] and our present data showing an acceleration of meiotic maturation by CPEB antibody injection are consistent with them. The discrepancy of the effect of CPEB antibody injection on oocyte maturation might be due to the use of different CPEB antibodies that do not recognize the same epitopes in the CPEB protein. As XGld2 associates with CPEB in stage VI oocytes [this study, 6.19.20], the data presented here are consistent with the presence of XGld2 in a masking complex with CPEB in oocytes. The antibodies, by interacting with their target proteins, could disrupt this masking complex, alleviate the repression and allow the translation of maturation-required proteins before the requirement of cytoplasmic polyadenylation. In agreement with this, ERK activation (reflecting Mos synthesis) by CPEB antibody injection without progesterone treatment (Fig.4F) strengthens the idea that perturbation of the repressive complex leads to the synthesis of Mos without the need of poly(A) tail elongation. Therefore, the complex bearing XGld2 and CPEB, already present in stage VI oocytes, could be considered as a masking complex.

CeGLD-2 polymerase activity is stimulated by interaction with the RNA binding protein, GLD3 [16]. In Xenopus oocytes, previous studies showed that CPEB and CPSF are RNA binding proteins that bring XGld2 to the $3^{\prime}$ end of mRNAs regulated by cytoplasmic polyadenylation [6.19]. Here, we identified XRbm9 as a new RNA binding protein that interacts with XGld2. We show that XRbm9 is a component of the polyadenylation complex with CPEB and CPSF. Hence, three RNA binding proteins interact directly with XGld2 and are present in the same complex. However, we cannot rule out the possibility that XRbm9 and XGld2 are in complexes independently of CPEB. More generally, different RNA binding proteins, interacting with Gld2, could connect the PAP to different type of RNA targets. We show that tethered XRbm9 stimulates translation of a reporter mRNA. THIS STIMULATION DOES NOT SEEM TO DEPEND ON THE PRESENCE OF XGLD2 AS OVEREXPRESSING WILD-TYPE OR CATALYTICALLY INACTIVE XGLD2 ALONG WITH MS2-XRBM9 DO NOT AFFECT THE TRANSLATIONAL ACTIVATION BY XRBM9. HOWEVER, WE CANNOT EXCLUDE THAT IN PHYSIOLOGICAL OR SPECIFIC CONDITIONS, XRBM9 IS ABLE TO TARGET XGLD2 TO SPECIFIC MRNA. 


\section{THE MOLECULAR MECHANISM UNDERLYING XRBM9-DEPENDENT}

TRANSLATIONAL ACTIVATION IS UNCLEAR AND AWAITS FURTHER INVESTIGATIONS.

The subcellular localization of the mammalian Rbm9 is not clear and depends on the isoform and the tissue examined but it appears to be mainly nuclear in cell lines and brain where, nevertheless, there is additional cytoplasmic expression [23.24]. Here, we identify an XRbm9 isoform expressed AT STEADY STATE in the oocyte cytoplasm. The amino-terminal most sequence of $\mathrm{XRbm} 9$ is particular as it is extended compare to the amino-terminal sequences identified in X.tropicalis, mammals, C.elegans and zebrafish. This peculiar sequence could be the mark of an oocyte-specific XRbm9 isoform. It is probable, however, that other XRbm9 isoforms are present in embryonic and adult tissues and that they display nuclear localization. XGLD2 IS EXPRESSED BOTH IN THE NUCLEUS AND THE CYTOPLASM WHEREAS XRBM9 IS ONLY DETECTED IN THE CYTOPLASM. THE NUCLEAR FUNCTION OF XGLD2 REMAINS UNSTUDIED BUT ITS ROLE COULD BE RELATED TO THE FUNCTION OF THE S. cerevisae TRF4 PROTEIN IN RNA QUALITY CONTROL. HOWEVER, THIS XGLD2 NUCLEAR FUNCTION SHOULD BE INDEPENDENT OF THE XRBM9 ISOFORM ISOLATED IN THIS STUDY.

Interestingly, recent studies showed that proteins involved in splicing as well as the exon junction complex could mediate the enhancing effect of splicing on mRNA translation [3436]. Rbm9, as a splicing factor interacting with a Poly(A) polymerase, could also participate to the translational enhancement mediated by introns. INDEED, THE PRESENCE OF THE PAP GLD2 ON THE MESSENGER, TARGETED BY A PROTEIN OF THE RBM9 FAMILY, COULD ALLOW THE POLYADENYLATION OF THE MESSENGERS REGULATED BY RBM9 HENCE ENHANCING THEIR TRANSLATION. Further studies would determine a potential role for Rbm9 in this kind of translational regulation.

In mammals, Rbm9 was identified as a repressor of tamoxifen activation of the estrogen receptor and as a gene upregulated by androgens [26.37]. Moreover, Underwood et al. [23] showed that $m R b m 9$ is expressed in the ovary whereas $m A 2 B P 1$ is not, and other particular Rbm9 splice variants appear to be specific to breast, ovary or other estrogen-sensitive tissues. Therefore, it would be of interest to examine whether, in oocytes, XRbm9 activity or localization could be regulated by progesterone. hRbm9 was shown to interact directly with the estrogen receptor [26]. In Xenopus, different receptors have been described to mediate oocyte maturation [38-40]. However, these steroid receptors are not detected in the membrane where progesterone signaling is initiated. More recently, a membrane progestin receptor 
(mPR) unrelated to nuclear steroid receptors was identified [41]. Investigating the possible interaction between XRbm9 and the progesterone receptor could lead us to uncover a link between progesterone and the cytoplasmic polyadenylation machinery.

\section{Materials and Methods}

\section{Xenopus oocytes and embryos}

Oocytes manipulations in MMR buffer and oocyte extracts in lysis buffer were performed as described in [42]. Manual oocytes enucleation was performed as described in [20]. Progesterone was used at $10 \mathrm{mg} / \mathrm{ml}$. For microinjections, the usual injected volume for antibodies and RNA was 20 to $40 \mathrm{nl}$ per oocyte and the number of injected oocytes is 35 for each condition. In vitro fertilization and embryo cultivation were carried out as described [43].

\section{Yeast two-hybrid screen}

A directional human embryonic cDNA library (Gift of N. Bonneaud) was used for the screen [44]. The human hGld2 bait plasmids were constructed by cloning the amino-terminal (amino acids 1-185) and the carboxy-terminal (amino acids 184-480) part of hGld2 $\Delta 8$ in frame with the Gal4 DNA binding domain (see supplemental data). Yeast two-hybrid screen was performed using the mating procedure described in [44]. After 3 to 5 days, the histidine positive clones were analyzed. PCR amplification of the inserts using pADGal4 specific primers was performed on the yeast colonies and PCR products were sequenced. Approximately $7 \times 10^{5}$ clones were screened and 90 clones were found to grow in absence of histidine. Inserts from 24 clones were sequenced and analyzed by BLAST comparison to the translated nucleotide sequence database.

\section{Antibodies and immunoblot analysis}

XGld2 and XRbm9 antibodies are directed against the following peptides respectively: $\mathrm{NH} 2-$ NTARAVYEKQKFD-COOH and NH2-SQGNQEPTATPDT-COOH. These antibodies were raised by injection of the thyroglobulin-coupled peptides (Sigma) into rabbits (New Zealand) and were affinity-purified. The antibody against Xenopus CPEB is an affinity-purified rabbit polyclonal antiserum [20]. The anti-RPA and anti-AuroraA antibodies were provided by J.M. Lemaitre and C. Prigent respectively. The anti-CPSF100 and anti-MS2 antibodies were provided by E. Wahle and P.G. Stockley, respectively. The anti-CPSF160, the anti-Mos and IgG antibodies were obtained from Santa Cruz (SC-28872, SC-086 and SC-2027, respectively). The anti-pTpY ERK-MAPK antibody was obtained from New England Biolabs 
(9106S). The anti $\beta$-tubulin and anti-HA antibodies were obtained from E7 (Iowa Hybridoma Bank) and 12CA5 (Abcam) hybridomas, respectively. For microinjections, purified antibodies were dialysed and used at $1 \mu \mathrm{g} / \mu \mathrm{l}$. Western blots were performed as described in [42].

\section{DNA constructs and RNA synthesis}

Expression and two hybrid constructs bearing XGld2, hGld2 XRbm9 and hRbm9 cDNA are described as supplementary material.

The pGBT9 AuroraA and the pGADGH-p17 were provided by Y. Arlot-Bonnemains [45].

The wild type mos 3'UTR reporter RNA construct was obtained from [20]. Capped mRNA encoding the different constructs were prepared by linearizing the pCS2 or pCSH-encoding ORFs [20] with Not1 and carrying out transcription reactions according to [46] and used at the initial concentration of $400 \mathrm{ng} / \mathrm{ml}$.

\section{Immunoprecipitations}

Protein oocyte extracts corresponding to 30 oocytes, RNAseA treatment and immunoprecipitations were performed as described [20]. Depending on the size of the protein, the samples were boiled or not, separated by SDS-PAGE and analyzed by Western blotting.

\section{Polyadenylation assay}

Oocyte total RNA was extracted using the Mini RNA Isolation II ${ }^{\mathrm{TM}}$ kit (Zymo Research) and the PAT assay was carried out according to [47]. Subsequent PCRs were carried out as in Rouget et al. (2006). The polyadenylation status of the mRNA encoding the X. leavis ribosomal protein S22 was analyzed by using the dT-PAT primer and a specific upstream primer (5'-GGGATCGTTTCCAGATGCG-3'). The PCR products were resolved in a $2.5 \%$ agarose gel and visualized by ethidium bromide staining.

\section{Tethering}

Control plasmids (pMSP, MS2-U1A and MS2-PABP) and the Luc-MS2 reporter were supplied by N. Minshall and N. Standart [29]. THE PLASMID ENCODING HA-MS2XGLD2 WAS SUPPLIED BY L. ROUHANA AND M. WICKENS [19]. Plasmids encoding the fusion proteins were linearized with HindIII. Luc-MS2 was linearized with BglII or with SpeI to obtain Luc $\Delta \mathrm{MS} 2 \mathrm{mRNA}$. Linearized DNA were transcribed using T7 RNA polymerase. Oocyte manipulation was performed as described above. Microinjections and luciferase assay were performed as described in Minshall et al (2001) except that oocytes were homogenized in $40 \mu 1 /$ oocyte in lysis buffer (Promega). The polyadenylation status of the LucMS2 and reporter mRNA were established as described above. PCR were performed 
using the dT-PAT primer and a specific upstream primer (primer 3: 5'CCTCGAGTCCGTTGAGAAGAAG-3'). The polyadenylation appears as a discrete band due to the experimental set up. The presence of the reporter mRNAs was assessed by PCR with 2 primers located in the firefly luciferase ORF (primer 1: 5'GGAAGCGACCAACGCCTTGAT-3' and primer 2: 5'-CCGCCCTTCTTGGCCTTTATG3'). The PCR products were resolved in a $2.1 \%$ agarose gel and visualized by ethidium bromide staining.

\section{Acknowledgments}

We thank N. Bonneaud for reagents, advice and assistance during the two-hybrid screen. We are grateful to Nicola Minshall and Nancy Standart for the tethering assay constructs AND TO MARVIN WICKENS AND LABIB ROUHANA FOR THE GIFT OF HA-MS2-XGLD2 AND HA-MS2-XGLD2 D242A. We thank Claude Prigent, Jean-Marc Lemaître and Peter G. Stockley for the gift of antibodies. We are grateful to E. Wahle and U. Kuehn for the gift of the unpublished anti CPSF100 antibody. We thank Y. Arlot-Bonnemains for the Maskinp17 and AuroraA two-hybrid constructs. We thank M. Simonelig for critical reading of the manuscript and J.M. Donnay and G. Herrada for technical assistance. This work was supported by the Centre National de la Recherche Scientifique and the Association pour la Recherche sur le Cancer (contract number 4469 and 3147 to E.M.). C.R. is supported by the Ministère de la Jeunesse, de l'Education Nationale et de la Recherche and by the Association pour la Recherche sur le Cancer.

\section{References}

1. Vasudevan, S., Seli, E. and Steitz, J.A. (2006). Metazoan oocyte and early embryo development program: a progression through translation regulatory cascades. Genes Dev 20, $138-46$.

2. Hake, L.E. and Richter, J.D. (1994). CPEB is a specificity factor that mediates cytoplasmic polyadenylation during Xenopus oocyte maturation. Cell 79, 617-27.

3. Stebbins-Boaz, B., Cao, Q., de Moor, C.H., Mendez, R. and Richter, J.D. (1999). Maskin is a CPEB-associated factor that transiently interacts with elF-4E. Mol Cell 4, 1017-27.

4. Minshall, N. and Standart, N. (2004). The active form of Xp54 RNA helicase in translational repression is an RNA-mediated oligomer. Nucleic Acids Res 32, 1325-34.

5. Nakahata, S., Kotani, T., Mita, K., Kawasaki, T., Katsu, Y., Nagahama, Y. and Yamashita, M. (2003). Involvement of Xenopus Pumilio in the translational regulation that is specific to cyclin B1 mRNA during oocyte maturation. Mech Dev 120, 865-80.

6. Barnard, D.C., Ryan, K., Manley, J.L. and Richter, J.D. (2004). Symplekin and xGLD-2 are required for CPEB-mediated cytoplasmic polyadenylation. Cell 119, 641-51. 
7. Kim, J.H. and Richter, J.D. (2006). Opposing polymerase-deadenylase activities regulate cytoplasmic polyadenylation. Mol Cell 24, 173-83.

8. Cao, Q. and Richter, J.D. (2002). Dissolution of the maskin-eIF4E complex by cytoplasmic polyadenylation and poly(A)-binding protein controls cyclin B1 mRNA translation and oocyte maturation. Embo J 21, 3852-62.

9. Charlesworth, A., Wilczynska, A., Thampi, P., Cox, L.L. and MacNicol, A.M. (2006). Musashi regulates the temporal order of mRNA translation during Xenopus oocyte maturation. Embo J 25, 2792-801.

10. Gebauer, F. and Richter, J.D. (1995). Cloning and characterization of a Xenopus poly(A) polymerase. Mol Cell Biol 15, 1422-30.

11. Ballantyne, S., Bilger, A., Astrom, J., Virtanen, A. and Wickens, M. (1995). Poly (A) polymerases in the nucleus and cytoplasm of frog oocytes: dynamic changes during oocyte maturation and early development. Rna 1, 64-78.

12. Wang, S.W., Toda, T., MacCallum, R., Harris, A.L. and Norbury, C. (2000). Cid1, a fission yeast protein required for S-M checkpoint control when DNA polymerase delta or epsilon is inactivated. Mol Cell Biol 20, 3234-44.

13. Read, R.L., Martinho, R.G., Wang, S.W., Carr, A.M. and Norbury, C.J. (2002). Cytoplasmic poly(A) polymerases mediate cellular responses to $\mathrm{S}$ phase arrest. Proc Natl Acad Sci U S A 99, 12079-84.

14. Saitoh, S., Chabes, A., McDonald, W.H., Thelander, L., Yates, J.R. and Russell, P. (2002). Cid13 is a cytoplasmic poly(A) polymerase that regulates ribonucleotide reductase mRNA. Cell 109, 563-73.

15. Kadyk, L.C. and Kimble, J. (1998). Genetic regulation of entry into meiosis in Caenorhabditis elegans. Development 125, 1803-13.

16. Wang, L., Eckmann, C.R., Kadyk, L.C., Wickens, M. and Kimble, J. (2002). A regulatory cytoplasmic poly(A) polymerase in Caenorhabditis elegans. Nature 419, 312-6.

17. Kwak, J.E., Wang, L., Ballantyne, S., Kimble, J. and Wickens, M. (2004). Mammalian GLD-2 homologs are poly(A) polymerases. Proc Natl Acad Sci U S A 101, 4407-12.

18. Nakanishi, T. et al. (2006). Possible role of mouse poly(A) polymerase mGLD-2 during oocyte maturation. Dev Biol 289, 115-26.

19. Rouhana, L. et al. (2005). Vertebrate GLD2 poly(A) polymerases in the germline and the brain. Rna 11, 1117-30.

20. Rouget, C., Papin, C. and Mandart, E. (2006). Cytoplasmic CstF-77 protein belongs to a masking complex with cytoplasmic polyadenylation element-binding protein in Xenopus oocytes. J Biol Chem 281, 28687-98.

21. Meyer, B.J. (2000). Sex in the wormcounting and compensating X-chromosome dose. Trends Genet 16, 247-53.

22. Jin, Y., Suzuki, H., Maegawa, S., Endo, H., Sugano, S., Hashimoto, K., Yasuda, K. and Inoue, K. (2003). A vertebrate RNA-binding protein Fox-1 regulates tissue-specific splicing via the pentanucleotide GCAUG. Embo J 22, 905-12.

23. Underwood, J.G., Boutz, P.L., Dougherty, J.D., Stoilov, P. and Black, D.L. (2005). Homologues of the Caenorhabditis elegans Fox-1 protein are neuronal splicing regulators in mammals. Mol Cell Biol 25, 10005-16.

24. Nakahata, S. and Kawamoto, S. (2005). Tissue-dependent isoforms of mammalian Fox-1 homologs are associated with tissue-specific splicing activities. Nucleic Acids Res 33, 207889.

25. Ponthier, J.L. et al. (2006). Fox-2 splicing factor binds to a conserved intron motif to promote inclusion of protein 4.1R alternative exon 16. J Biol Chem 281, 12468-74.

26. Norris, J.D., Fan, D., Sherk, A. and McDonnell, D.P. (2002). A negative coregulator for the human ER. Mol Endocrinol 16, 459-68. 
27. Coller, J.M., Gray, N.K. and Wickens, M.P. (1998). mRNA stabilization by poly(A) binding protein is independent of poly(A) and requires translation. Genes Dev 12, 3226-35.

28. Gray, N.K., Coller, J.M., Dickson, K.S. and Wickens, M. (2000). Multiple portions of poly(A)-binding protein stimulate translation in vivo. Embo J 19, 4723-33.

29. Minshall, N., Thom, G. and Standart, N. (2001). A conserved role of a DEAD box helicase in mRNA masking. Rna 7, 1728-42.

30. Minshall, N., Walker, J., Dale, M. and Standart, N. (1999). Dual roles of p82, the clam CPEB homolog, in cytoplasmic polyadenylation and translational masking. Rna 5, 27-38.

31. Stebbins-Boaz, B., Hake, L.E. and Richter, J.D. (1996). CPEB controls the cytoplasmic polyadenylation of cyclin, Cdk2 and c-mos mRNAs and is necessary for oocyte maturation in Xenopus. Embo J 15, 2582-92.

32. Barkoff, A.F., Dickson, K.S., Gray, N.K. and Wickens, M. (2000). Translational control of cyclin B1 mRNA during meiotic maturation: coordinated repression and cytoplasmic polyadenylation. Dev Biol 220, 97-109.

33. de Moor, C.H. and Richter, J.D. (1999). Cytoplasmic polyadenylation elements mediate masking and unmasking of cyclin B1 mRNA. Embo J 18, 2294-303.

34. Sanford, J.R., Gray, N.K., Beckmann, K. and Caceres, J.F. (2004). A novel role for shuttling SR proteins in mRNA translation. Genes Dev 18, 755-68.

35. Wiegand, H.L., Lu, S. and Cullen, B.R. (2003). Exon junction complexes mediate the enhancing effect of splicing on mRNA expression. Proc Natl Acad Sci U S A 100, 11327-32.

36. Nott, A., Le Hir, H. and Moore, M.J. (2004). Splicing enhances translation in mammalian cells: an additional function of the exon junction complex. Genes Dev 18, 210-22.

37. Lieberman, A.P., Friedlich, D.L., Harmison, G., Howell, B.W., Jordan, C.L., Breedlove, S.M. and Fischbeck, K.H. (2001). Androgens regulate the mammalian homologues of invertebrate sex determination genes tra-2 and fox-1. Biochem Biophys Res Commun 282, 499-506.

38. Tian, J., Kim, S., Heilig, E. and Ruderman, J.V. (2000). Identification of XPR-1, a progesterone receptor required for Xenopus oocyte activation. Proc Natl Acad Sci U S A 97, 14358-63.

39. Bayaa, M., Booth, R.A., Sheng, Y. and Liu, X.J. (2000). The classical progesterone receptor mediates Xenopus oocyte maturation through a nongenomic mechanism. Proc Natl Acad Sci U S A 97, 12607-12.

40. Lutz, L.B., Cole, L.M., Gupta, M.K., Kwist, K.W., Auchus, R.J. and Hammes, S.R. (2001). Evidence that androgens are the primary steroids produced by Xenopus laevis ovaries and may signal through the classical androgen receptor to promote oocyte maturation. Proc Natl Acad Sci U S A 98, 13728-33.

41. Zhu, Y., Bond, J. and Thomas, P. (2003). Identification, classification, and partial characterization of genes in humans and other vertebrates homologous to a fish membrane progestin receptor. Proc Natl Acad Sci U S A 100, 2237-42.

42. Papin, C., Rouget, C., Lorca, T., Castro, A. and Mandart, E. (2004). XCdh1 is involved in progesterone-induced oocyte maturation. Dev Biol 272, 66-75.

43. Newport, J. and Kirschner, M. (1982). A major developmental transition in early Xenopus embryos: I. characterization and timing of cellular changes at the midblastula stage. Cell 30, 675-86.

44. Zhou, R. et al. (2002). SOX9 interacts with a component of the human thyroid hormone receptor-associated protein complex. Nucleic Acids Res 30, 3245-52.

45. Pascreau, G., Delcros, J.G., Cremet, J.Y., Prigent, C. and Arlot-Bonnemains, Y. (2005). Phosphorylation of maskin by Aurora-A participates in the control of sequential protein synthesis during Xenopus laevis oocyte maturation. J Biol Chem 280, 13415-23. 
46. Papin, C. and Smith, J.C. (2000). Gradual refinement of activin-induced thresholds requires protein synthesis. Dev Biol 217, 166-72.

47. Salles, F.J. and Strickland, S. (1995). Rapid and sensitive analysis of mRNA polyadenylation states by PCR. PCR Methods Appl 4, 317-21.

\section{Supplementary material}

Fig.S1: Sequence alignment of XRbm9, hRbm9 and RTA

Fig.S2: XRbm9 antibody specificity

Fig.S3: XRbm9 antibody injection effect on cytoplasmic polyadenylation

Fig.S4: XGld2 antibody characterization and XGld2 $\Delta 4$ predicted amino acid sequence Complementary Materials and Methods

\section{Figure legends}

Fig.1. Identification of Rbm9, a novel Gld2-interacting protein. (A) Schematic representation of the hGld 2 fusion proteins used for the two-hybrid screen. The amino- or carboxy-terminal moieties of hGld2 (hGld2N and hGld2C respectively) were expressed as fusion proteins with the Gal4 binding domain (Gal4BD) and used together for the screen. (B) Growth of transformed yeast in selective medium. Bait plasmids (left) were mated with prey plasmids (top). In addition to hGld2N and hGld2C, bait plasmids included the empty bait plasmid (pGBT9), full length hGld2 and the kinase AuroraA. Prey plasmids included the empty prey plasmid (pADGal4), hRbm9 (clone 12 from the screen), a negative control obtained from the screen (clone 5) and Maskin p17. AuroraA-Maskin p17 interaction serves as positive control. Double transformants growing on medium lacking tryptophan, leucine and histidine (-W-L$\mathrm{H})$, indicating an interaction, are designated by + . Double transformants which did not grow are indicated by -. (C) Schematic representation of XRbm9 sequence and comparison with $\mathrm{hRbm} 9$ isolated in the screen. The two proteins carry two different carboxy-terminal domains (dark or light grey, respectively) due to alternative splicing. Sequence similarity in the RRM is indicated (\%). For sequence comparison between XRbm9 and hRbm9, see Fig.S1. (D) Total, nuclear and cytoplasmic protein extracts were analyzed by Western blotting with the indicated antibodies. The RPA, exclusively expressed in the nucleus, serves as enucleation control. (E) Immunoblot analyses of Xenopus oocyte extracts (left panel) and embryo extracts (right panel) with XRbm9 and $\beta$-tubulin antibodies. The $\beta$-tubulin, consistently expressed throughout oocyte maturation and embryogenesis, serves as a loading control. (D,E) XRbm9: In vitro translated $\mathrm{XRbm} 9$ serves as migration size control. Protein sizes are indicated (kDa). 
Fig.2. XRbm9 is part of a complex with XGld2, CPEB and CPSF. (A,B) Gld2-Rbm9 interaction in yeast two-hybrid system. The two-hybrid system was used to determine interactions between the indicated constructs. Gld2 constructs were expressed as fusion proteins with the Gal4BD and Rbm9 constructs were expressed as fusion proteins with the Gal4 activation domain (Gal4AD). Double transformants growing on medium lacking tryptophan, leucine and histidine, indicating an interaction, are designated by + . Double transformants negative for the growth are indicated by -. (C-E) Coimmunoprecipitation experiments in presence of RNaseA. Oocyte extracts alone (E), overexpressing HA-tagged $\mathrm{XRbm} 9 \Delta \mathrm{N}$ (C) or HA-tagged XGld2 (D) were immunoprecipitated as indicated and the immunoprecipitates were analyzed by Western blotting as indicated. THE EQUIVALENT OF ONE OOCYTE WAS LOADED AS INPUT.

Fig.3. Tethered XRbm9 is able to stimulate translation in Xenopus oocytes. (A) Oocytes expressing MS2, MS2-U1A, MS2-XRbm9 or MS2-PABP fusion proteins were injected either with Luc-MS2 and Renilla luciferase mRNAs (dark grey) or with Luc- $\Delta$ MS2 and Renilla luciferase mRNAs (light grey). The translation of the reporter mRNAs was determined by a dual luciferase assay. Luciferase activity was plotted (the ratios of firefly/Renilla luciferases activities in the presence of the fusion proteins are shown relative to the activity with the MS2 alone, set at 1). The mean values of 3 different experiments are shown. For each experiment, 3 to 5 pools each containing 3 to 5 oocytes were assayed per experimental point, and mean values and standard deviations were determined. (B) MS2-fusion proteins expression in reticulocytes (RRL) and oocytes by Western blotting using MS2 antibody. In oocytes, MS2PABP co-migrates with a non-specific band (star) when compared to the migration of in vitro translated MS2-PABP. (C) OOCYTES EXPRESSING MS2, MS2-XRBM9, HA-MS2XGLD2 FUSION PROTEINS OR COEXPRESSING MS2-XRBM9 AND HA-XGLD2 D242A OR MS2-XRBM9 AND HA-XGLD2WT WERE INJECTED WITH LUC-MS2 AND RENILLA LUCIFERASE MRNAS. THE TRANSLATION OF THE REPORTER MRNAS WAS DETERMINED BY A DUAL LUCIFERASE ASSAY. (D) HA-MS2-XGLD2, HAXGLD2DA AND HA-XGLD2WT PROTEINS EXPRESSION IN OOCYTES BY WESTERN BLOTTING USING ANTI-HA ANTIBODY.

Fig.4. XGld2 and CPEB antibody injections accelerate the G2/M transition in oocytes. (A) Characterization of the XGld2 antibody. (Top panel) Western blot analysis of overexpressed 
HA-XGld2 or XGld2 in oocytes or endogenous XGld2 in stage VI (StVI) or mature (MII) oocytes with the XGld2 antibody. (Middle panel) Immunoprecipitates from XGld2overexpressing (overexp. XGld2) or stage VI (endogen. XGld2) oocytes with XGld2 antibody or a control IgG were analyzed by Western blotting as indicated. The star indicates a nonspecific band. (Bottom panel) Oocyte extracts were immunoprecipitated and analyzed by Western blotting as indicated. THE EQUIVALENT OF ONE OOCYTE WAS LOADED AS INPUT (B) Oocytes were injected with XGld2 or non-specific (IgG) antibodies or left uninjected. After $1 \mathrm{~h}$ incubation, maturation was induced with progesterone $(\mathrm{Pg})$ and the percentage of GVBD was scored at the indicated time and plotted. This graph is representative of 5 experiments. (C) Immunoblot analysis of Mos, AuroraA, activated MAPK (PP ERK) and b-tubulin levels in oocytes collected during an experiment depicted in A. A significant increase in Mos and AuroraA protein synthesis and ERK biphosphorylation was observed in XGld2 antibody-injected oocytes (XGld2 Ab) as soon as 1.5 hours after progesterone treatment compared to the 4 hours for the control oocytes (IgG). (D,E) Similar experiments as in $\mathrm{B}$ and $\mathrm{C}$ respectively using the CPEB antibody. (F) Oocytes were injected with XGld2, CPEB or non-specific (IgG) antibodies. After 16h incubation without progesterone, the activation status of the MAPK (PP ERK) was assessed by Western blot. The mature oocyte (MII) serves as a control of ERK activation. Noteworthy, XGld2 antibody injection did not trigger MAPK activation in absence of progesterone.

Fig.5. XGld2 is required for cytoplasmic polyadenylation. (A,B) Polyadenylation assay in oocytes. (A) Oocytes were injected with mos 3'UTR RNA and 30-min later were injected with XGld2 or CPEB antibodies (Ab) or with nonspecific IgG (IgG) or left uninjected (no $\mathrm{Ab})$. After $1 \mathrm{~h}$ incubation, maturation was induced with progesterone. Total RNA was extracted from pools of 5 oocytes collected at the time of progesterone addition $(\mathrm{Ab} t 0)$ or when $30 \%$ of control oocytes have undergone GVBD. Total RNA was submitted to mos polyadenylation analysis (PAT assay) using specific primers. This gel is representative of 5 experiments. (B) Kinetic of mos 3'UTR polyadenylation. Oocytes were injected with XGld2 antibody or nonspecific IgG and treated as in A. The mos 3'UTR polyadenylation status was assessed at the indicated time after progesterone $(\mathrm{Pg})$ addition. In this experiment, $30 \%$ of oocytes underwent GVBD at the $5 \mathrm{~h}$ time point. The polyadenylation status of the endogenous S22 RNA in the same samples was not affected by the antibodies injection (negative control). Fragment sizes (M) are indicated on the right in base pair (bp). 
Figure 1

A

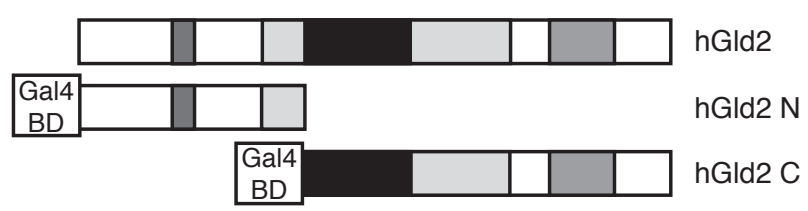

$\square$ NLS $\square$ Central $\quad$ Catalytic $\square$ PAP/25A
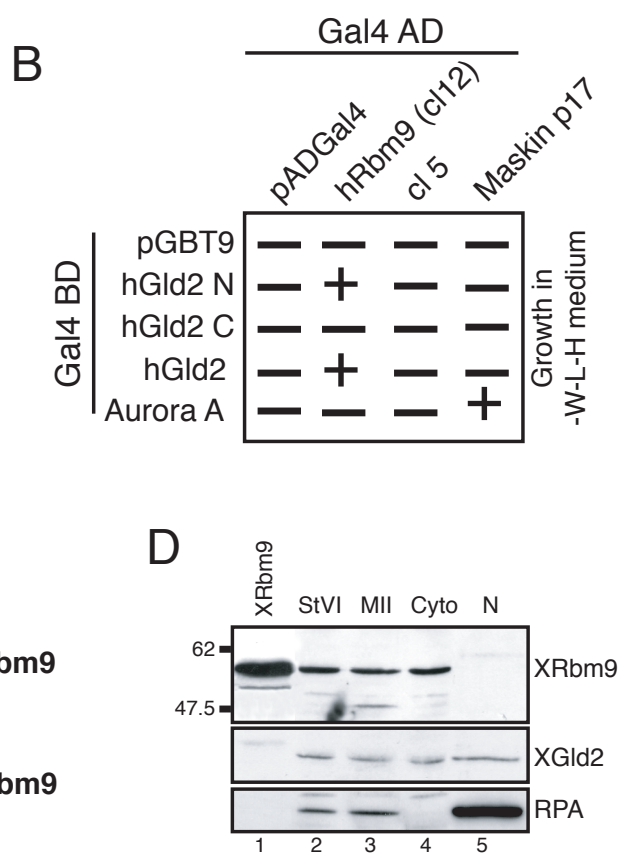

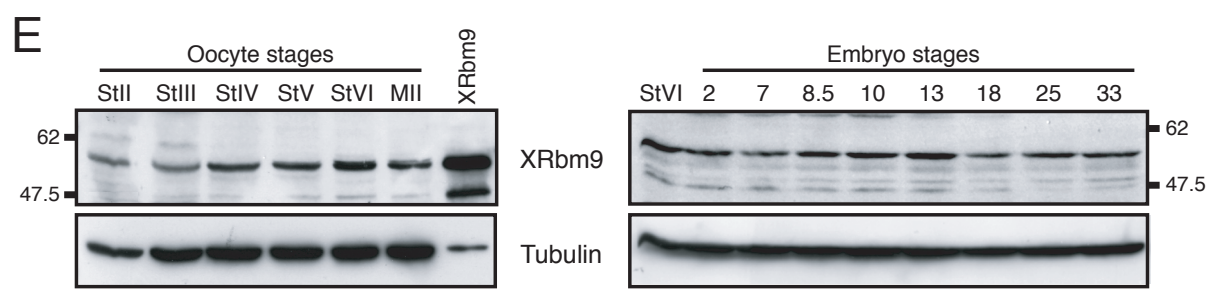




\section{Figure 2}

A

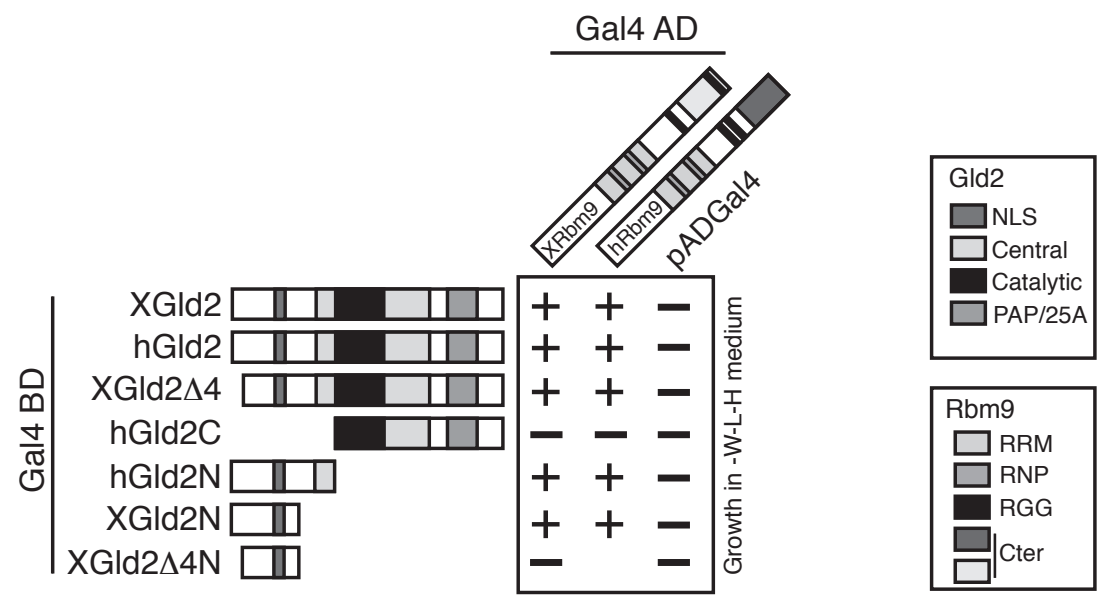

B

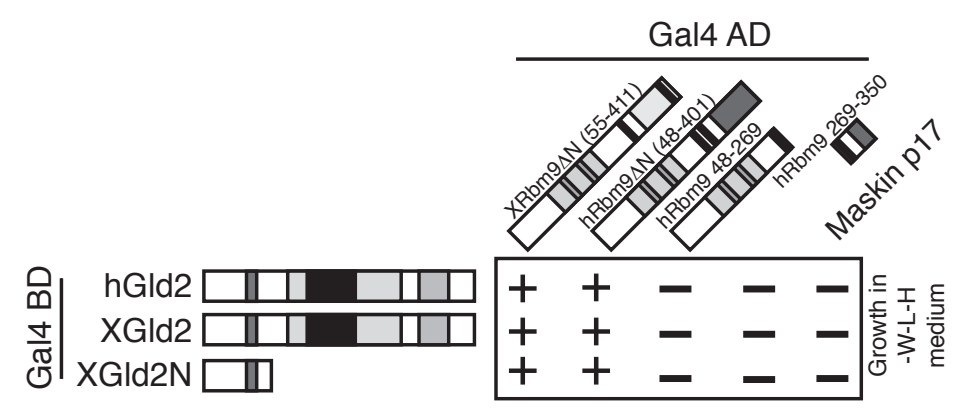

C HA-XRbm9 $9 \mathrm{~N}$ overexpression

D HA-XGld2 overexpression
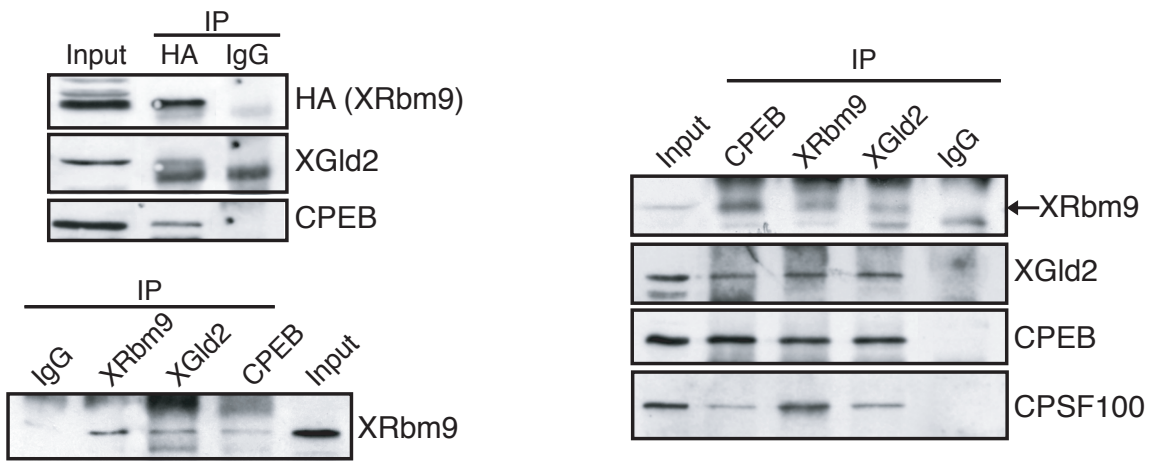

$E$ endogenous proteins

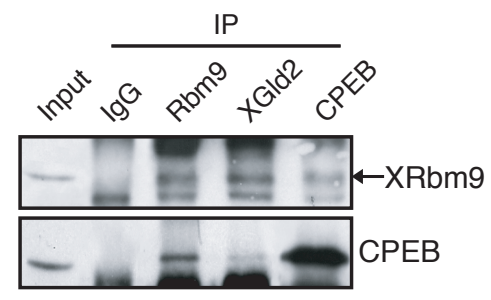


Figure 3 revised
A

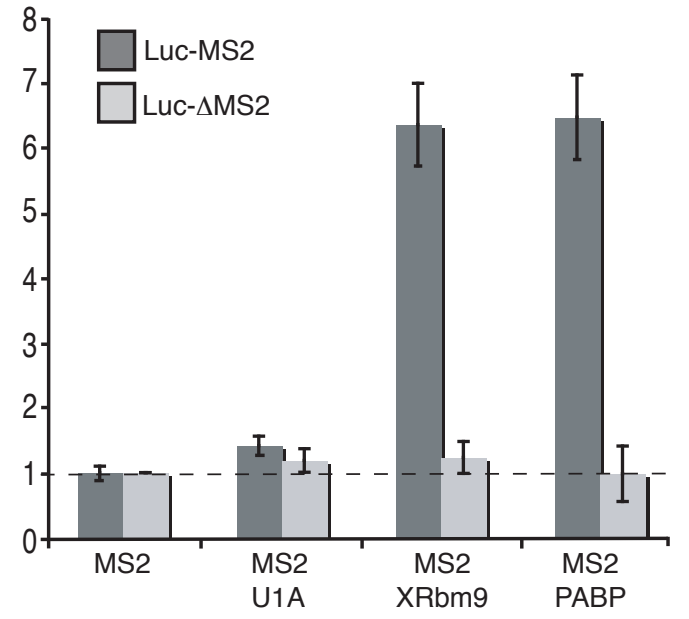

C

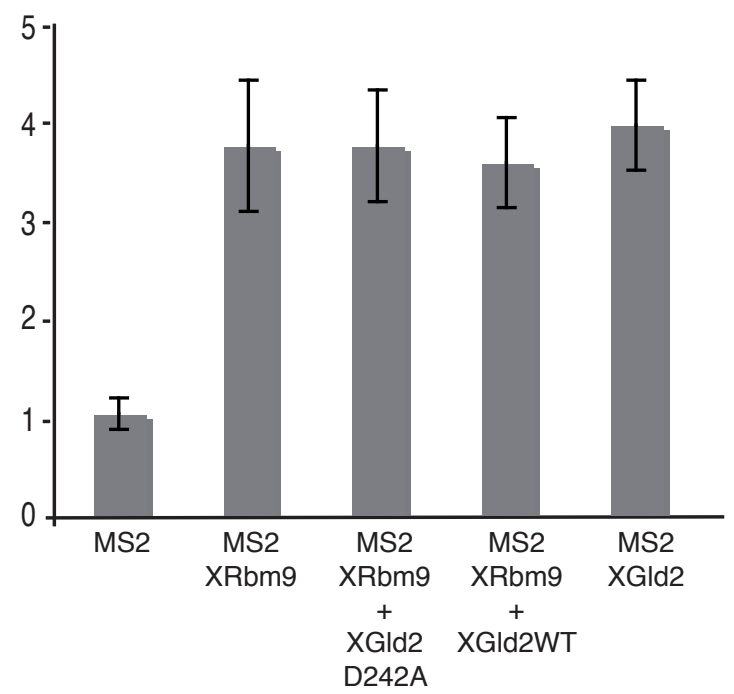

B
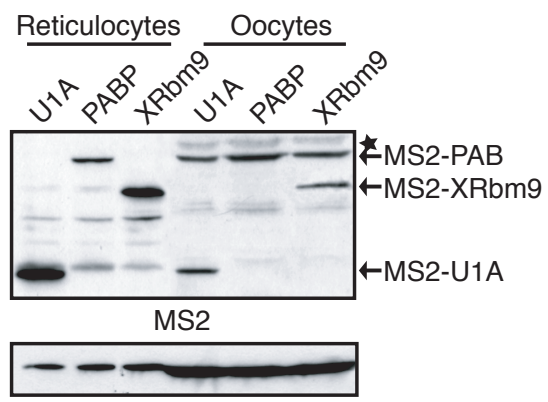

Tubulin
D

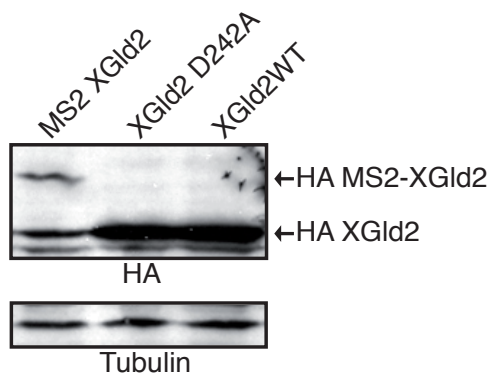


Figure 4

A
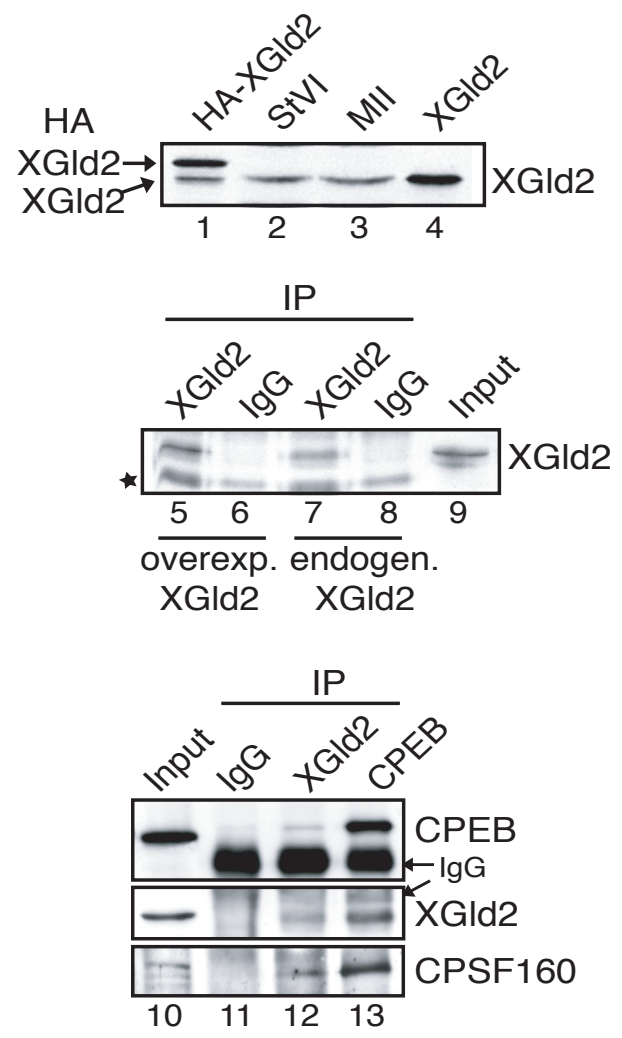

D

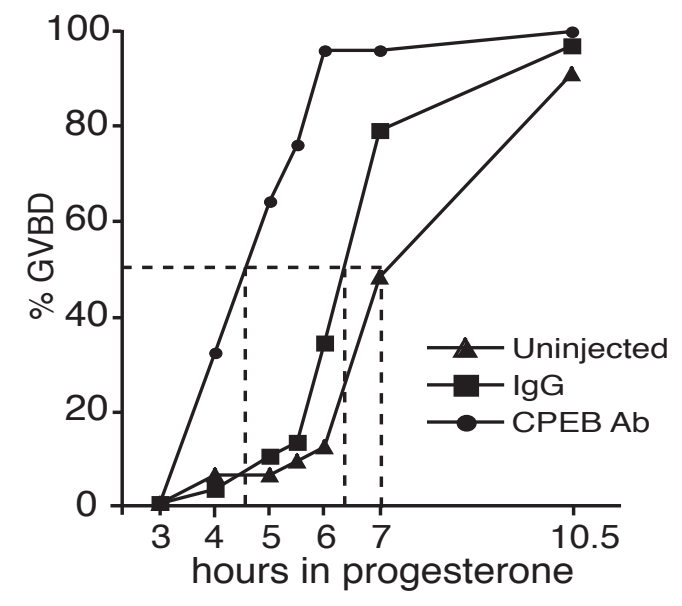

B

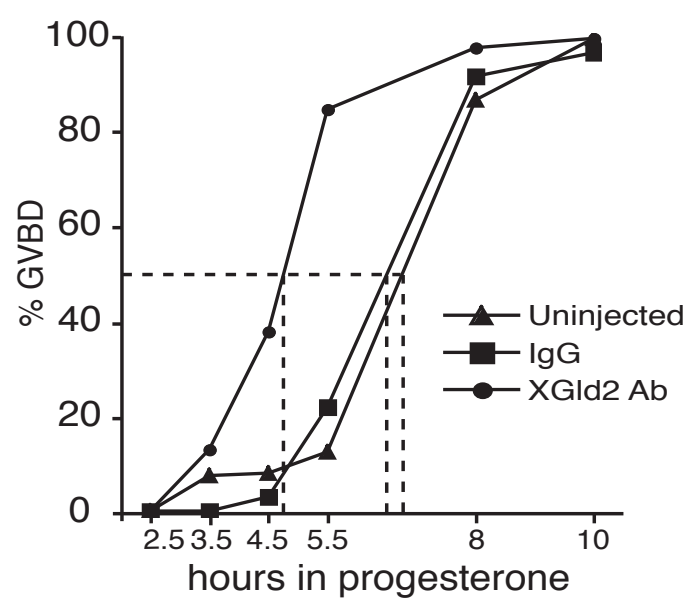

C

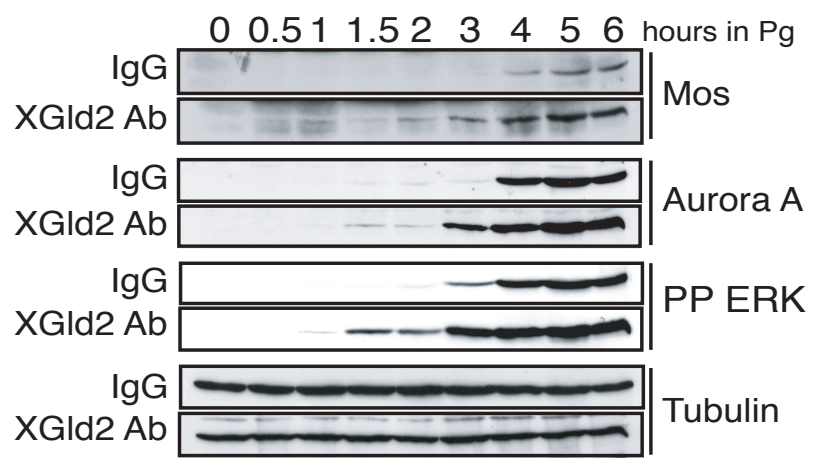

E

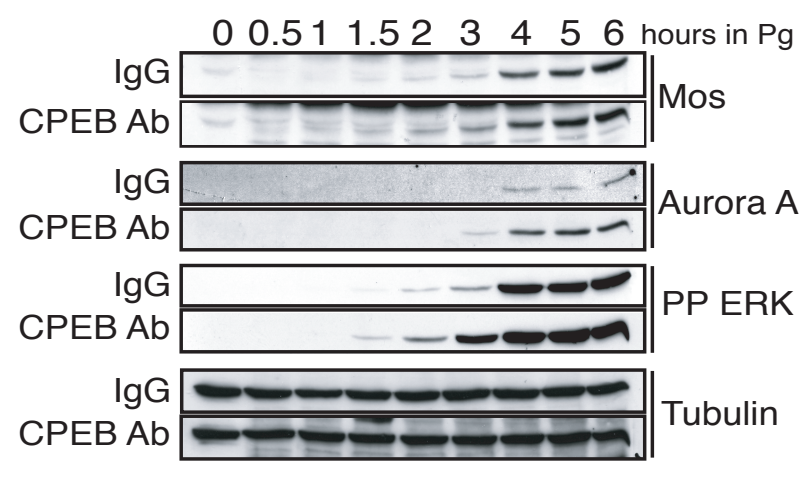

F

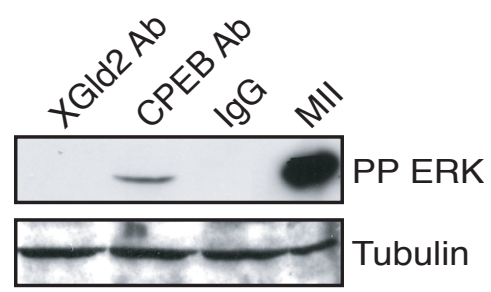


Figure 5

A
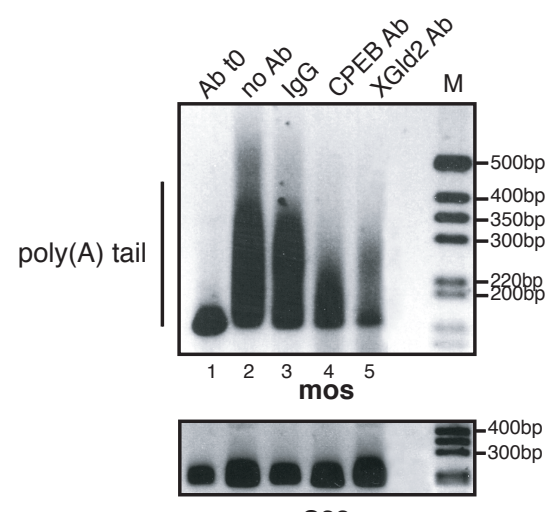

S22

B

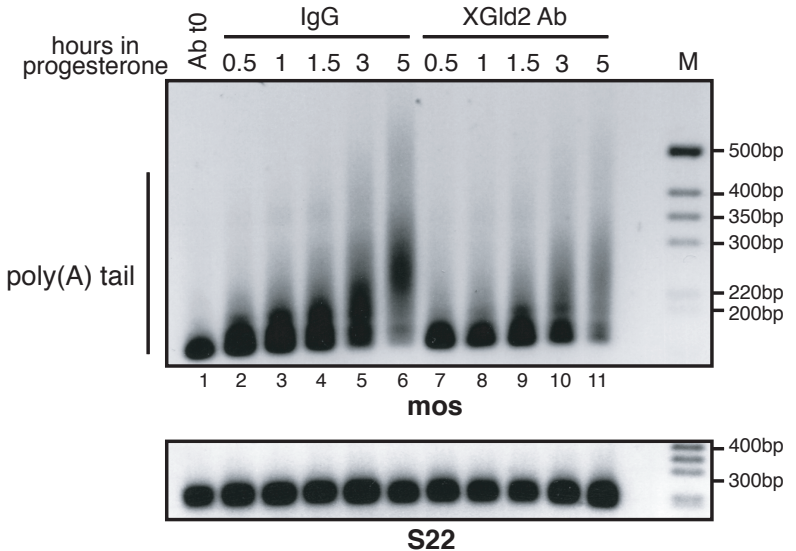

